Studia i Materiały, 2013 (16): 103-111

\title{
Kulturowy wymiar fuzji i przejęć
}

\author{
Paulina Gawryszewska*
}

Artykut stanowi przeglad literatury na temat znaczenia kultury organizacyjnej w procesach potaczeń i przejęć w przedsiębiorstwach o charakterze międzynarodowym. Autorka prezentuje badania nad kultura $w$ organizacji i zarzqdzaniu oraz opisuje motywy i przestanki przeprowadzania fuzji i przejęć. Przytaczajac wyniki badań, ukazuje z jednej strony kulture jako jedna z głównych przyczyn niepowodzeń w przeprowadzaniu połaczeń, z drugiej zaś - wskazuje na jej niewykorzystany potencjat $w$ skomplikowanych warunkach zmian. Dodatkowo określa jak sprawnie przeprowadzić proces integracji $w$ sytuacji fuzji i przejęcia, podając przykład praktycznych narzędzi i teorii, mogacych mieć zastosowanie $w$ codziennym funkcjonowaniu firmy po połaczeniu bądź przejęciu.

Kluczowe słowa: kultura organizacyjna, fuzje, przejęcia, proces integracji, zmiana organizacyjna.

Nadesłany: 26.09.2013 | Zaakceptowany do druku: 15.11.2013

\section{The cultural dimension of mergers and acquisitions}

The article is a review of the literature on the importance of organizational culture in mergers and acquisitions $(M \& A)$ processes at international companies. The author presents research on culture in organization and management fields and also discusses reasons for carrying out $M \& A$. On the one hand the author considers culture one of main factors contributing to failure to merge on the other she shows its untapped potential in complicated conditions of changes in a company. Additionally the author defines what a successful integration process in M\&A is giving examples of practical tools and theories which can be used in daily running of firm after a merger or an acquisition.

Key words: organizational culture, mergers, acquisitions, integration, organizational change.

Submitted: 26.09.2013 | Accepted: 15.11.2013

JEL: M14

\footnotetext{
Mgr Paulina Gawryszewska - Studia doktoranckie, Wydział Zarządzania UW.

Adres do korespondencji: Wydział Zarządzania, Uniwersytet Warszawski, ul. Szturmowa 1/3, 02-678 Warszawa; e- mail: pgawryszewska@diplomats.pl.
} 


\section{Wprowadzenie}

Kontekst kulturowy nabiera obecnie szczególnego znaczenia w organizacjach o charakterze międzynarodowym. Dzieje się to głównie na skutek wchodzenia przez firmy na nowe rynki poprzez połączenia lub przejęcia. Wiele przedsiębiorstw traktuje dzisiaj fuzje i przejęcia jako jeden z najbardziej powszechnych i znaczących procesów gospodarczych w skali światowej, pozwalający na zwiększenie potencjału przedsiębiorstwa i będący jednym ze sposobów na realizację strategii firmy na rynkach międzynarodowych bądź światowych.

Procesy fuzji i przejęć jako specyficzny przykład zmian organizacyjnych, wiążących się z koniecznością reorganizacji na dużą skalę, pokazuja, że kultura może być zarówno czynnikiem ułatwiającym, jak i hamujacym te zmiany (Glinka, 2010). W procesy te bardzo często zaangażowane są firmy z różnych kręgów kulturowych. Nawet jeśli łączą się przedsiębiorstwa $\mathrm{z}$ tego samego kręgu, to mają one odmienne kultury organizacyjne. Co właśnie sprawia, że wymiar kulturowy obok kontekstu ekonomiczno-finansowego i prawnego staje się istotnym aspektem każdej fuzji bądź przejęcia i odpowiada za jego przebieg oraz powodzenie. Zróżnicowanie kulturowe może wpływać tak pozytywnie, jak i negatywnie na przeprowadzanie zmian organizacyjnych. Dlatego tak ważne jest, aby zaprojektować i wdrożyć zmiany, które będa akceptowalne $\mathrm{z}$ punktu widzenia wszystkich pracowników.

\section{Przegląd badań nad kulturą w organizacji i zarządzaniu}

Wśród badaczy nie ma zgodności co do rozumienia kultury, choć zajmuje ona należne miejsce w teorii organizacji i zarządzania oraz antropologii. Wczesne definicje kultury były wyliczeniami jej elementów składowych i taka też była pierwsza naukowa definicja kultury, autorstwa Edwarda Taylora: „Kultura, względnie cywilizacja, wzięta w najszczerszym sensie etnograficznym, jest złożoną całością zawierającą wiedzę, wierzenia, sztukę, moralność, prawo, obyczaj oraz wszystkie inne zdolności i przyzwyczajenia nabyte przez człowieka jako członka społeczeństwa" (Burszta, 1998 w: Glinka i Kostera, 2012, s. 65). Nurt kulturowy w zarządzaniu, defi- niując kulturę, wyszczególnia kilka rodzajów określeń, ujmowanych z różnych perspektyw epistemologicznych. Ze względu na wielość i różnorodność interpretacji w swoim artykule odniosę się do klasyfikacji, wprowadzonej przez Lindę Smircich (1983). Badaczka, szeroko zainteresowana sposobem rozumienia kultury w publikacjach na temat zarządzania, na podstawie przeglądu literatury, wyodrębniła trzy kategorie jej pojmowania: kultura jako zmienna niezależna, jako zmienna zależna i jako metafora rdzenna. Dwa pierwsze podejścia są zorientowane na stan, trzeci zaś - traktuje kulturę jako proces.

Rozumienie kultury jako zmiennej niezależnej, charakterystyczne jest dla zarządzania międzykulturowego i utożsamia ją z kulturą danego kraju, w którym funkcjonuje, a więc traktowana jest ona jako czynnik wyjaśniający. Kultura postrzegana jest jako element otoczenia, który wywiera wpływ na organizację. Ujmowanie kultury jako zmiennej niezależnej możemy znaleźć na przykład w publikacjach Geerta Hofstede, a szczególnie w jego słynnej pracy pt. Kultury i organizacje (2000/1980). Na podstawie przeprowadzonych badań ilościowych w różnych filiach firmy IBM, Hofstede sporządził mapę różnic kulturowych w obrębie czterech wymiarów kultury: indywidualizm/kolektywizm, męskość/ kobiecość, dystans władzy i unikanie niepewności, którą w nowszych wydaniach uzupełnił o piąty wymiar - orientację długoterminową. Pomimo dużego wpływu teorii Hofstede na rozwój badań nad różnicami kulturowymi i ich oddziaływaniem na zarządzanie, jest ona również obiektem krytyki. Jedni uważają, że model jest zbyt ogólny i wewnętrznie sprzeczny (McSweeney, 2002 w: Glinka i Kostera, 2012). Inni krytykują go za to, że nie opiera się on na założeniach teoretycznych i przypisuje miary ilościowe czynnikom niemierzalnym (Cray i Mallory, 1998). Podkreśla się również, że Hofstede traktuje pojęcie narodu jako cechowanego przez historyczny determinizm, homogeniczność i statyczność (Kwek, 2003; Holden, 2002 w: Kostera i Śliwa, 2012).

W ramach perspektywy zorientowanej na stan, definiuje się kulturę jako zmienną wewnętrzną, podsystem organizacji będący obiektem zarządzania. Organizacje ,wytwarzają" kultury i „wpływają” na nie (Kostera, 2003). Kultura w tym rozumieniu definio- 
wana jest jako unikatowy sposób działania w firmie lub jako społeczny klej spajający firmę (Aniszewska, 2007). Kultura jest zatem traktowana jako ekspresja tego, co członkowie organizacji mają wspólnego: podzielanych wartości czy wzorców zachowań. Rozumienie kultury jako zmiennej wewnętrznej spopularyzowali Peters i Waterman (1982) w swoim bestselerze pt. W poszukiwaniu doskonatości oraz Deal i Kennedy (1982) w książce pt. Corporate Culture. W swoich definicjach silnie łączyli oni kulturę organizacyjną ze strategią, akcentując przy tym rynkowy wymiar tej zależności. Peters i Waterman uważali, że odpowiednio zaprojektowany i utrzymywany podsystem kulturowy może zwiększyć efektywność funkcjonowania przedsiębiorstwa, dzięki zacieśnieniu więzi między jej pracownikami oraz poprawą komunikacji wewnętrznej. Sprowadzało to rozumienie kultury, do tego, co widoczne. Ponieważ postulaty tych badaczy były postrzegane jako zalecenia konsultanckie, nie zaś twierdzenia naukowe, obecnie nie są już pożądane. Jedynym autorem przypisanym do tego nurtu, utrzymującym swą pozycję wśród badaczy doradztwa, jest Edgar Schein (1985/2004), który wyróżnił trzy poziomy kultury: założenia, normy i wartości oraz artefakty. Według Scheina kultura ,jest zestawem podstawowych założeń - wspólnych rozwiązań uniwersalnych problemów dotyczących zewnętrznej adaptacji i wewnętrznej integracji, które ewaluowały z upływem czasu i są przekazywane z pokolenia na pokolenie" (Kostera i Śliwa, 2012, s. 82). Kostera (2012) zwraca uwagę, że definicja Scheina pokazuje, iż każda kultura próbuje znaleźć odpowiedź na te same pytania, przy równoczesnej różnorodności tychże odpowiedzi. Ale ta różnorodność sprawia właśnie, że w jednej firmie kultura może stać się źródłem przewagi konkurencyjnej, w drugiej natomiast stwarzać warunki wymarzone do pracy, a dla kolejnej stanowić źródło innowacyjności.

Ujmowanie kultury jako zmiennych: niezależnej i wewnętrznej nie współgra $\mathrm{z}$ pojęciem kontekstu kulturowego i było krytykowane $\mathrm{z}$ powodu instrumentalnego jej traktowania (Smircich, 1983). Kultura widziana jako zmienna zewnętrzna traktowana jest statycznie, jako zestaw wskaźników, które należy wziąć pod uwagę przy projektowaniu systemów zarządzania, jednocześnie nie pomaga w zrozumieniu jego sensu, skupiając się głównie na dostosowaniu organizacji do kultury narodowej (Kostera i Śliwa, 2012). Spojrzenie na kulturę jako zmienną wewnętrzną współgra z poszukiwaniem kontekstu kulturowego, ale na poziomie postaw i wartości pracowników, a więc traktuje kulturę jak narzędzie komunikacji.

Najbardziej przydatnym w konceptualizacji zjawiska kultury było trzecie podejście, wyróżnione przez Lindę Smircich, definiujące kulturę jako metaforę rdzenną, epistemologiczną, charakterystyczne dla perspektywy zorientowanej na proces. Jako metafora rdzenna, kultura oznacza, że z czegoś co „organizacja ma” staje się „czymś, czym organizacja jest” (Kostera, 1996). Badanie organizacji jako kultury to czerpanie $\mathrm{z}$ antropologii kultury, co daje możliwość skupienia się na ludzkiej stronie organizacji. Dzięki temu można obserwować w sposób dynamiczny motywacje, wartości, postawy, wzorce zachowań. Jest to ujęcie psychodynamiczne, pozwalające na obserwację zjawisk w czasie. Za pomocą „opisu gęstego" dąży się do przedstawienia zjawisk w ich żywym kontekście. Kontekst zatem jest integralną częścią badania organizacji, łączy interpretację uczestników z szerszymi procesami.

Badacze przyjmujący tę perspektywę, wychodzą zazwyczaj z klasycznej definicji kultury, autorstwa antropologa, Cifforda Geertza: „Przyjmując [...], że człowiek jest zwierzęciem rozpostartym w sieciach znaczeń, które sam uplót1, patrzę na kulturę jako na te sieci, a jej analizie wobec tego służy nie eksperymentalna nauka poszukująca praw, lecz interpretująca, poszukująca znaczeń" (Kostera, Śliwa, 2012, s. 249). Ale formułują też własne, jak na przykład, znana badaczka zarządzania, Barbara Czarniawska-Jorges, według której „kultura jest otoczką pokrywającą świat, którą zarówno tworzymy, jak i w której żyjemy. Jej błona okrywa wszystko, na co spojrzymy; jest to [...] środowisko (społecznego) życia" (Kostera i Śliwa, 2012, s. 249).

Kultura jako metafora rdzenna pozwala odejść od analogii przeprowadzanych między organizacją i maszyną lub organizacją i organizmem. Jest to odejście od porównań ze światem fizycznym i przejście do porównań ze społecznym fenomenem.

Jak podkreśla Paweł Krzyworzeka tradycyjne podejścia postrzegają kulturę w kategoriach stabilności, powszechności 
Tabela 1. Koncepcje kultury

\begin{tabular}{|c|c|}
\hline Stare & Nowe sposoby rozumienia kultury \\
\hline $\begin{array}{l}\text { - kultura jest niezmienna, w stanie sta- } \\
\text { łej równowagi lub samoreprodukują- } \\
\text { ca się } \\
\text { - społeczności są homogeniczne } \\
\text { - kultury to jednorodne, statyczne, } \\
\text { niewielkie całości } \\
\text { - kulturę można sprowadzić do zesta- } \\
\text { wu zdefiniowanych cech } \\
\text { - nacisk kładzie się na system wspól- } \\
\text { nych wszystkim znaczeń: „autentycz- } \\
\text { na kultura” }\end{array}$ & $\begin{array}{l}\text { - kultura jest aktywnym procesem tworzenia znaczeń } \\
\text { - miejsca nie są zamrożone - ludzie korzystają z powią- } \\
\text { zań lokalnych, narodowych i globalnych } \\
\text { - idee nigdy nie tworzą zamkniętych ani spójnych całości } \\
\text { - ludzie w różny sposób usytuowani w relacjach spo- } \\
\text { łecznych i procesie dominacji korzystają z dostępnych } \\
\text { im środków ekonomicznych i instytucjonalnych, aby } \\
\text { własną definicję sytuacji uczynić trwałą i nie dopuścić } \\
\text { do rozpowszechnienia innych definicji } \\
\text { - kultura jako spójna, systematyczna, oparta na kon- } \\
\text { sensusie, jako przedmiot, poza ludzką sprawczością, } \\
\text { nieideologiczna - jest wersją hegemoniczną }\end{array}$ \\
\hline
\end{tabular}

Źródło: Kostera (2008, s. 66) na podstawie: Wright (1998).

i homogeniczności, nowsze zaś akcentuja jej dynamikę, zmienność i różnorodność oraz usytuowanie w kontekście relacji społecznych. Odwołując się do takiego rozróżnienia, autor uważa, że można, za Wright (1998), podzielić definicje kultury na stare i nowe.

\section{Procesy fuzji i przejęć - główne definicje i założenia}

Klasyczna definicja fuzji (merger) mówi, że jest to proces, na mocy którego dwa autonomiczne przedsiębiorstwa łączą się w celu powstania nowej firmy, aby osiągnąć wspólne cele biznesowe (Frąckowiak 2009). Z przejęciem (acquisition) mamy natomiast do czynienia, kiedy dochodzi do transferu kontroli od jednego przedsiębiorstwa do drugiego na skutek zdobycia przez akcjonariuszy odpowiedniej liczby udziałów, wystarczającej do zarządzania i kontroli (Herdan, 2005). W literaturze anglojęzycznej, najczęściej używanym terminem na określenie fuzji i przejęć jest Mergers \& Acquisitions - skrót: M\&A, którym posługuję się w dalszej części artykułu (Pocztowski, 2004). Oba te procesy znane są gospodarce od stuleci. Pierwsze udokumentowane alianse gospodarcze miały miejsce w XV i XVI wieku. W gospodarkach krajów rozwiniętych procesy fuzji i przejęć następują cyklicznie, a ich przebieg wyznacza kondycja światowej gospodarki (Ławniczak, 2012; Frąckowiak, 2009; Lewandowski, 2001).

Złożoność fuzji i przejęć oraz różnorodność form, w jakich te procesy się przeja- wiają sprawia również, że przesłanek ich przeprowadzania jest wiele. Celem nadrzędnym w fuzji lub przejęciu jest maksymalizacja zysku, osiagana poprzez realizację strategii firmy. W procesie M\&A firmy najczęściej dążą do (Schmidt, 2001):

- większych możliwości produkcyjnych,

- dostępu do nowych technologii,

- rozszerzenia gamy nowych produktów,

- dostępu do pracowników o kluczowych kompetencjach,

- redukcji kosztów operacyjnych,

- poprawy pozycji rynkowej,

- uzyskania pozycji lidera,

- zwiększenia udziału w rynku. Oprócz procesów M\&A majacych miejsce na arenie światowej, warto również zwrócić uwagę na nasze krajowe podwórko. Zdaniem Lewandowskiego (2001), czynnikami specyficznymi dla polskiego rynku fuzji i przejęć, odróżniającymi nas od rynków innych krajów, są:

- specyficzni uczestnicy rynku kontroli;

- związek fuzji i przejęć z prywatyzacją;

- udział inwestorów zagranicznych w transakcjach na rynku kontroli;

- przebieg i struktura transakcji;

- ewoluujący model rynku kontroli.

Za czynnik kreujaccy alianse i przejęcia strategiczne w naszym kraju podaje się szybką i skuteczną ekspansję oraz fakt, że stanowimy duży rynek z możliwym do ukształtowania popytem. Szybki rozwój gospodarki, niskie koszty finansowania i dostępność nowych instrumentów finansowych przyczyniają się do wzrostu liczby M\&A na polskim rynku (IBM, 2007; Lewandowski, 2001). Inwestorzy zagra- 
niczni oprócz wsparcia kapitałowego wnoszą do takich firm także nowe technologie i know-how, aby ułatwić spółkom dostęp do rynków zbytu. Liczba fuzji/przejęć w Polsce swój szczyt osiągnęła w 2008 roku, choć średnia wartość transakcji była niższa niż na rynku światowym. Transakcje o najwyższej wartości zrealizowano w branży finansowej, telekomunikacji, nieruchomościach i energetyce; odwrotnie niż to miało miejsce na rynkach światowych. Działo się tak głównie za sprawą specyfiki przemian i konieczności modernizacji oraz konsolidacji branż Jest to również typowe dla gospodarek wschodzących, o dużym potencjale rynku i popytu konsumpcyjnego, intensywnych procesach prywatyzacji oraz korzyściach skali w przemyśle i branżach surowcowych (Ławniczak, 2012; Raport KPMG, 2011; IBM, 2007).

\section{Kultura organizacyjna w procesach fuzji i przejęć}

Pomimo że procesy M\&A stały się codziennością we współczesnej rzeczywistości biznesowej wciąż wiele $\mathrm{z}$ nich nie przynosi oczekiwanych rezultatów. $\mathrm{Z}$ analizy literatury wynika, że przyczyny porażek procesów M\&A odnoszą się głównie do fazy integracji po połaczeniu lub przejeciu i jej zarządzaniu (Stahl, Madenhall, 2005; Pablo, Javidan, 2004; Morosino, 1998). Jednocześnie prezentowane wyniki badań w tym zakresie wykazują, że do głównych powodów, dlaczego firmy zaangażowane w proces fuzji i przejęć nie osiagają zaplanowanych wyników (Clayton, 2010; Galpin, Herndon, 2007; Jackson, Schuler, 2003; Schimdt, 2001), zalicza się brak zrównoważenia trzech kluczowych elementów: strategii, kultury i praktyk biznesowych (Jacobs, 2003). Okazuje się, iż wśród przyczyn niepowodzeń fuzji i przejęć blisko połowa odnosi się do uwarunkowań kulturowych, między innymi takich jak (Pocztowski, 2004):

- niedocenianie trudności połączenia odrębnych kultur;

- niewystarczająca wiedza o kulturze organizacyjnej partnera;

- liczne konsekwencje nieudolnej integracji kulturowej.

W badaniach przeprowadzonych przez Pocztowskiego (2004) respondenci uznali, że dopasowanie kultur organizacyjnych powinno stanowić istotne kryterium selek- cji partnera M\&A, uzasadniając: ,,[zgodność kulturowa] to kluczowy czynnik sukcesu”, „zwiększa efektywność”, „można wtedy stosować jednolitą politykę personalną, spójny styl zarządzania”, „,system komunikacji jest wówczas efektywniejszy, łatwiej rozwiązywać konflikty w firmie", „łatwiej dostosować obie kultury do siebie, ze względu na krótszy okres dojścia do planowanych wyników" (Pocztowski, 2004, s. 73-74). Ponadto kultura organizacyjna zawiera czołowe miejsce na liście najważniejszych problemów czy przeszkód w fazie integracji (Baughn i Finzel, 2009; Tewes, 2001). Badania Kaya i Shelton (2000) pokazały, że krytycznymi składnikami procesu integracji po fuzji są: utrzymanie w firmie najbardziej utalentowanych pracowników (76\%), utrzymanie w firmie czołowych menedżerów $(67 \%)$ oraz integracja kultur organizacyjnych $(51 \%)$. Przytoczone powyżej wyniki badań wyraźnie wskazuja na znaczenie i wagę kultury w organizacji zarówno przed podjęciem decyzji o fuzji lub przejęciu, jak i w czasie budowania już nowej firmy. Szczególnie ważne jest uświadomienie sobie, jakie zmiany w kulturze organizacji mogą wywołać międzynarodowe fuzje i przejęcia, które uznaje się za jeden z najbardziej skomplikowanych procesów organizacyjnych w życiu firmy.

Opisy fuzji i przejęć redukowane są głównie do strony finansowo-prawnej, a także realizowania misji i celów strategicznych. Zazwyczaj definiuje się je poprzez pryzmat zysku, a pomija się aspekty kulturowe (Whitaker, 2011; Giffords i Dina, 2003). A przecież połączenie się lub przejeccie dwóch różnych przedsiebiorstw to nie tylko osiągnięcie zaplanowanych wyników finansowych. To przede wszystkim zderzenie się kultur organizacyjnych zarówno w sytuacji połączenia się firm z różnych kręgów kulturowych, jak i na terenie jednego państwa, gdy pojawiają się firmy o różnych strategiach, strukturach i stylach zarządzania. Chciałabym zwrócić uwage na fakt, że nie kierując się motywami kulturowymi przy wyborze partnera M\&A, zakładamy świadomość podobieństw i bliskości kulturowej, co w rezultacie powoduje trudniejsze zarządzanie, gdyż eliminuje potrzebę uczenia się i rozumienia różnic (Aniszewska, 2008; Schorg, Raiborn i Massoud, 2004). Oprócz braku zrozumienia lub akceptacji przez pracowników nowych zasad mogą pojawić się także różnice $\mathrm{w}$ organizacji 
pracy, w języku, zachowaniu i systemach wartości poszczególnych pracowników.

Wzrost świadomości znaczenia kultur organizacji podczas połączenia bądź przejęcia powinien prowadzić do konkretnych działań, mających na celu ustalenie podobieństw i różnic między partnerami procesu M\&A. Jak sugeruje Pocztowski (2004), przebieg tych działań powinien być następujący:

- określenie przedmiotu badania, wybór technik i narzędzi badawczych oraz źródeł informacji (w fazie przygotowań);

- przeprowadzenie badań, opracowanie wniosków i wstępnej wersji planu integracji (np. w ramach due diligence);

- uzupełnienie wiedzy w zakresie różnic i podobieństw, korekta planu oraz monitorowanie i ewentualnie korygowanie przebiegu procesów integracyjnych (po zawarciu M\&A).

Jak wskazuje autor, w sytuacji międzynarodowych fuzji i przejęć, aby poznać potencjalnego partnera zagranicznego i oszacować prawdopodobieństwo sukcesu integracji obu firm w pierwszej kolejności powinno się zrozumieć i porównać fundamentalne wartości tkwiące w kulturach organizacyjnych partnerów. Przed podjęciem decyzji o fuzji lub przejęciu osoby zarządzające firmami bądź decydenci powinni przede wszystkim poznać odpowiedź na pytania: czy możliwa jest integracja kulturowa partnerów, jaki będzie jej prawdopodobny przebieg i czy można oczekiwać, że kultury wzajemnie się zasymilują bądź jedna zastapi drugą? Cartwright i Cooper (1996, s.79-90) zwracają uwagę, że odpowiedzią mogą być dwa możliwe scenariusze. Pierwszy, w którym silniejszy partner narzuca swoje rozwiązania i oczekuje dostosowania się drugiej strony, co najczęściej występuje w sytuacji przejęć. I drugi: w przypadku połączenia, gdzie firmy żywią przekonanie, że są partnerami i w związku $\mathrm{z}$ tym będą dążyć do integracji kultur organizacyjnych, co ma przynieść obopólne korzyści. Jednakże zarówno w jednym, jak i w drugim przypadku przedsiębiorstwa powinny dysponować odpowiednim rodzajem zdolności, pozwalających na sprawne zaprojektowanie zmian. W przypadku fuzji sukces zależy od stopnia, w jakim obie strony są w stanie współpracować i integrować się. W przejęciach sukces uwarunkowany jest zdolnościami nabywcy do zmiany kultury nabywanego. W obu sytuacjach znacze- nie może odgrywać zarówno trafna ocena dystansu kulturowego, dzielącego łączące się organizacje, jak i kultura kraju pochodzenia firm.

$\mathrm{Z}$ badań przeprowadzonych przez Pocztowskiego (2004) wynika, że główne aspekty procesów fuzji i przejeć, których znajomość ma istotne znaczenie dla nowo powstałej organizacji, to:

- wpływ kultury organizacyjnej na przeprowadzenie zmian, czyli wiedza o tym, jak określony typ kultury może wpłynąć na przebieg zmian;

- sposób zarządzania procesem integracji kulturowej, czyli to, w jaki sposób będą tworzone i kształtowane wzorce kulturowe, jakie działania służą integracji pracowników, wzmacniają ich motywację i zaangażowanie, jak monitorować proces integracji, kiedy i jakie działania korygujące podjąć.

Jak zaznacza Glinka (2010， s. 63), pomimo że „kultura pełni pozytywną rolę w procesie zmian, skupia wokół wspólnych wartości i nie pozwala zatracić tego, co w organizacji najważniejsze", może ona również doprowadzić to zamknięcia kulturowego. Co to oznacza w praktyce? Zarówno sytuację, kiedy nie poszukuje się nowych rozwiązań, zakładając, że to co działa i jest już znane, jest lepsze od nowego i nieznanego. Ponadto wartości zakorzenione w kulturze zamiast inspirować do działań i zbliżać ludzi mogą koncentrować uwagę pracowników na kwestiach drugorzędnych, z punktu widzenia wzajemnej integracji. W sytuacji procesów M\&A może również wystąpić zjawisko dysonansu, prowadzące do ujawniania odmiennych sposobów myślenia, norm i wartości i w konsekwencji doprowadzające do wzajemnych rozgrywek pomiędzy grupami uczestników zmian organizacyjnych.

Aniszewska (2007) zwraca uwagę, że integracja kultur w sytuacji fuzji czy przejęć jest kwestią umiejętności czerpania $\mathrm{z}$ różnych wartości organizacji. I tak, kiedy dochodzi do przejęcia firmy, inwestor powinien włączyć firmę przejmowaną w struktury organizacji. W przypadku firmy przejmowanej decydujące znaczenie ma przywiazanie do własnych podstawowych wartości kulturowych i atrakcyjność inwestora. Wzajemna integracja kulturowa może się udać jedynie wtedy, gdy obie strony będą chciały uczyć się od siebie nawzajem i dążyć do osiągnięcia synergii. 
Wybór drogi dostosowania kulturowego w fuzjach i przejęciach zależał będzie zatem od podejścia inwestora (geocentrycznego, etnocentrycznego, policentrycznego) i oceny akceptowalnego ryzyka związanego $\mathrm{z}$ integracją kultur.

Zdaniem Ławniczka (2012) różnice kulturowe mogą być źródłem kształtowania wartości pod warunkiem, że uzna się różnorodność kulturową partnerów i będzie ona sprawnie zarządzana przez głównych menedżerów. W warunkach międzynarodowych fuzji i przejęć wpływ na ich przebieg mają umiejętności i gotowość menedżerów do odgrywania roli inicjatora zmian i komunikowania strategii zmian. Autor twierdzi, że należy wdrażać procesy komunikacji już na etapie planowania fuzji/przejęcia, a skończyć na wszystkich zadaniach, związanych $\mathrm{z}$ integracja. Sprawna komunikacja może okazać się pomocna na linii zarządzający - szeregowi pracownicy. Z jednej strony może ona pomóc rozwiać wątpliwości co do przyszłości organizacji, zmniejszając tym samym niepewność pracowników i przedstawiając przeprowadzane zmiany w pozytywnym świetle. Z drugiej zaś - może okazać się przydatna w przekazywaniu najbardziej trudnych aspektów fuzji/przejęć, czyli zwolnień, zmiany stanowiska czy zakresu kompetencji. Dodatkowo menedżerowie mogą starać się pokazać pracownikom spojrzenie na proces $M \& A$, jak na sytuację niosącą nowe szanse i możliwości.

\section{Zarządzanie kulturą w fuzjach i przejęciach}

Na skutek połączeń i przejęć mamy $\mathrm{w}$ przedsiębiorstwach do czynienia ze zjawiskiem zróżnicowania kulturowego, z którym mocno koresponduje teoria kompetencji międzykulturowych, autorstwa Slawomira Magali (2011). Zdaniem profesora kompetencje kulturowe to swego rodzaju zestaw narzędzi, który samodzielnie kompletują wszyscy uczący się ludzie, poruszający się pośród różnych kultur i subkultur (np. w wielokulturowym miejscu pracy). To także zdolność rozumienia i pokonywania różnic w oprogramowaniu kulturowym. Dlatego kompetencje kulturowe wymagają rozszyfrowania kodów poznawczych, relacyjnych, emocjonalnych i równoczesnego porównywania ich. Dodatkową korzyścią $\mathrm{z}$ rozwijania tego rodzaju kompetencji jest fakt, że pozwalają one dostrzec wyraź- niej, jak bardzo złożone i zróżnicowane wewnętrznie są kultury organizacyjne $\mathrm{i}$ jak w wielu przypadkach członkowie organizacji mogą je stosować. Nic nie stanowi lepszej ilustracji kompetencji międzykulturowych, niż działania podjęte na skutek zmian organizacyjnych narzuconych z zewnątrz, które są następnie sabotowane od wewnątrz przez kompetentnych pracowników.

Teoria kompetencji kulturowych w praktyce może przełożyć się na przeprowadzenie audytu kulturowego w firmach po M\&A, zapobiegając tym samym przyszłym katastrofom i podwyższając bardzo małą liczbę fuzji i przejęć, które kończą się sukcesem. Audyt kulturowy ma za zadanie wyposażyć menedżera lub konsultanta, biorącego udział w fuzji lub przejęciu, w narzedzie pozwalajace rozpoznać lokalne ramy w organizacjach. Chodzi o to, żeby zrozumieć kultury organizacyjne i sposób, w jaki z nich ludzie korzystają. Ponieważ zderzenia kultur i rozdźwięk między wartościami kulturowymi a praktyką unaoczniają się wyraźnie w przypadku zmian organizacyjnych, jakimi są fuzje i przejęcia, dlatego audyt ma stanowić analizę porównawczą tych konkretnych kultur i instrument ich oceny. W przypadku fuzji bądź przejęcia należy zwracać uwagę na:

- kulturowe dopasowanie przedsiębiorstw:

- preferencje odnośnie do stylu kierowania;

- stopień planowania, formalizacji;

- nagradzanie, karanie;

- perspektywe czasowa;

- orientację na wzrost;

- na potencjał kulturowy obu łączących się podmiotów:

- potencjal innowacji;

- potencjał zaufania;

- potencjał współzależności;

- potencjał integracji.

W zarządzaniu międzykulturowym, obecnym w firmach powstałych w wyniku połączeń i przejęć, przydatna może się okazać także koncepcja Adler wyróżniajaca trzy modele kształtowania relacji między kulturami, istniejących w ramach organizacji: dominację, współistnienie oraz współpracę kulturową. Dominacja kulturowa polegająca na narzuceniu wszystkim jednostkom w organizacji jednolitych wzorców kulturowych i ignorowaniu innych wartości. Współistnienie kulturowe rozumiane jako poszukiwanie kompromisu między różnymi 
kulturami, oparte na akceptacji różnorodności. Współpraca kulturowa mająca na celu zbudowanie nowej, wspólnej kultury, akceptowanej przez wszystkich pracowników nowej instytucji. Z kolei Andrzej K. Koźmiński (2004) zwraca uwagę, iż aby zespół wielokulturowy mógł sprawnie funkcjonować, należy jego zarządzanie oprzeć na następujących zasadach:

- refleksyjności - pozwalającej na zastanowienie się nad źródłami wielokulturowości;

- empatii - czyli wczuciu się w percepcje, emocje i motywy innych pracowników organizacji;

- uznania różnorodności - czyli uznania prawa do odmienności;

- wspólnoty - rozumianej jako aktywne prawo do poszukiwania wspólnych interesów i motywacji i w konsekwencji budowania poczucia wspólnoty;

- kompromisu - czyli zanegowania uznania absolutnej nienaruszalności wszystkich aspektów danej kultury;

- stałej adaptacji - jako konieczności ciągłych dostosowań się pojawiających subkultur;

- szybkości działania - czyli natychmiastowego reagowania na zmiany związane z kulturą.

Fuzje i przejęcia jako szczególny przypadek zmian organizacyjnych, prowadzą do zwiększenia różnorodności kulturowej przedsiębiorstwa, która może utrudniać codziennie funkcjonowanie, a nawet przeprowadzenie procesu połączenia. $\mathrm{W}$ tej sytuacji firmy odwołuja się do różnych rozwiązań. Jedne próbują „przymykać oko" na tego rodzaju trudność, doprowadzając tym samym do eskalacji problemu. Inne oczekują na wzajemne dotarcie się i powstrzymują się od interwencji, tam gdzie nie dochodzi do konfliktów. Najskuteczniejszym rozwiązaniem wydaje się być aktywne działanie podczas procesu zmiany. Choć i ono może okazać się niewystarczające, kiedy uczestnicy procesu M\&A nie mają poczucia wspólnoty i wprowadzana zmiana, ich zdaniem, pozbawiona jest sensu. Bądź wtedy, kiedy decyzja o fuzji i przejęciu została podjęta pochopnie i nie wzięto pod uwagę różnic w głównych założeniach kultury łączących się organizacji. Jak podaje Glinka (2010), żadne z przytoczonych rozwiązań nie jest tak naprawdę dobre, żeby mogło wpłynąć na sprawne przeprowadzanie połączenia lub przejęcia.
Jej zdaniem pierwszym warunkiem sukcesu jest już na etapie przeprowadzania zmiany rozpoczęcie szkoleń i treningów adaptacyjnych oraz odpowiednia komunikacja dostosowana do potrzeb i preferencji różnych odbiorców. Następnie należy monitorować sama zmiane, czyli reagować na pojawiające się wątpliwości i konflikty pomiędzy odmiennymi kulturami. Przykładem dobrej praktyki jest także rozwinięcie nowego programu kulturowego ze wspólnymi wartościami i symbolami. Dzięki temu pracownicy mogą identyfikować się z nową organizacją. Ważne jest również, aby nowe praktyki włączyć do codziennych obowiązków. Dzięki temu wzrasta zaangażowanie pracowników w budowanie nowej misji i wizji firmy (Ławniczak, 2012).

\section{Podsumowanie}

Kwestie kultury organizacyjnej stają się coraz istotniejsze w sytuacji umiędzynarodowienia działalności przez przedsiębiorstwa. Wchodzenie na nowe rynki wymaga jednak od firm wypracowania takich norm i wartości, które $\mathrm{z}$ jednej strony uwzględnią specyfikę lokalną, z drugiej zaś - pozwolą na spójne działanie różnych części organizacji.

Literatura przedmiotu mocno podkreśla, że połączenia i przejęcia mają charakter szczególnych zmian organizacyjnych. I dlatego na kulturę organizacji, zaangażowaną w procesy M\&A, patrzy się wielowymiarowo. Sama kultura w organizacji i zarządzaniu może być traktowana jako element otoczenia, narzędzie komunikacji oraz metafora rdzenna. Jak pokazały przytoczone wyniki badań różnych autorów, kultura organizacyjna jest jednym z kluczowych czynników odpowiedzialnych za powodzenie procesu połączenia lub przejęcia. I to ona jednocześnie jest jednym z głównych wymiarów przedsiębiorstwa, które albo się pomija przy budowaniu nowej firmy, albo wykorzystuje się ją w sposób powierzchowny i nieudolny. Dlatego pomocne w tej sytuacji mogą się okazać audyty kulturowe i specjalnie zaprojektowane szkolenia oraz sesje treningowe, pozwalające na wzajemne poznanie się kultur łączonych bądź przejmowanych przedsiębiorstw. Niezwykle ważna jest także odpowiednia komunikacja pomiędzy zarządzającymi a szeregowymi pracownikami. W przypadku fuzji i przejęć zna- 
czenie ma rozumienie różnic $\mathrm{w}$ kulturach organizacyjnych firm i traktowanie ich z wyczuciem. To właśnie kultura organizacyjna może być mechanizmem tonującym reakcje pracowników na nowe warunki, jak również wyznaczać kierunek zmian. Może ona mieć służebne znaczenie wobec realizowanej strategii i wizji zmian. Jak ujmuje to Aniszewska ,jest ona mechanizmem warunkującym poziom zaufania i otwartości na nowe warunki” (2007, s. 216).

\section{Bibliografia}

Aniszewska, G. (2008). Kształtowanie kultury organizacyjnej w organizacjach międzynarodowych w sytuacji fuzji i przejęć. Zarzadzanie zasobami ludzkimi, 6 .

Aniszewska, G. (2007). Kultura organizacyjna w zarzadzaniu. Warszawa: PWE.

Baughn, M.K. i Finzel, P.A. (2009). A clash of cultures in a merger of two acquisition offices. Engineering Management Journal, 21(2), 11-17.

Cartwright, S. i Cooper, C.L. (1996). Managing mergers, acquisitions and strategic alliances. Integrating people and cultures. Oxford: Butterworth - Heinemann.

Clayton, B. (2010). Understanding the Unpredictable: beyond traditional research on mergers and acquisitions. E:CO Issue , 12(3), 1-19.

Cray, D. i Mallory, G.R. (1998). Making sense of managing culture. London: International Thompson Business Press.

Frąckowiak, W. (red.). (2009). Fuzje i przejęcia. Warszawa: PWE.

Galpin, T.J. i Herndon, M. (2007). The complete guide to mergers and acquisitions. (2nd Edition). San Francisco: Jossey-Bass.

Giffords, E. i Dina, R. (2003). Changing organizational culture: The challenge in forging successful mergers. Administration in Social Work, 27(1), 69-81.

Glinka, B. i Kostera, M. (red.). (2012). Nowe kierunki $w$ organizacji i zarzadzaniu: organizacje, konteksty, procesy zarzadzania. Warszawa: Wolters Kluwers.

Glinka, B. i Jelonek, A.W. (red.). (2010). Zarzadzanie międzykulturowe. Kraków: Wydawnictwo Uniwersytetu Jagiellońskiego.

Herdan, A. i Antolak, L. (2005). Potaczenia przedsiębiorstw: teoria i praktyka. Kraków: Księgarnia Akademicka.

Jackson, S.E. i Schuler, R.S. (2003). Managing human resources through strategic partnership. Ohio: Thomson Learning.
Jacobs, R. (2003). Successful mergers balance culture, strategy and business practices. Pobrano $\mathrm{z}$ : http://mworld.mce.be.

Kay, L. i Shelton, M. (2000). The people problem in mergers. The McKinsey Quarterly, 4.

Kostera, M. i Śliwa, M. (2012). Zarzadzanie w XXI wieku: jakość, twórczość, kultura. Warszawa: Wolters Kluwer.

Kostera, M. (2003). Antropologia organizacji. Warszawa: PWN

Kostera, M. (1996). Postmodernizm w zarządzaniu. Warszawa: PWE.

Koźmiński, A.K. (2004). Zarzadzanie w warunkach niepewności. Warszawa: PWN.

Lewandowski, M. (2001). Fuzje i przejęcia w Polsce na tle tendencji światowych. Warszawa: Wig-Press.

Ławniczak, R. (2012). Komunikowanie strategiczne $w$ międzynarodowych fuzjach i przejęciach. Poznań: Wydawnictwo Naukowe Contact.

Morosino, P. (1998). Managing cultural differences: effective strategy and execution across cultures in global corporate alliances. New York: Pergamon.

Pablo, A.L. i Javidan, M. (2004). Mergers and acquisitions: creating integrative knowledge. Oxford: Blackwell.

Pocztowski, A. (red.). (2004). Zarzadzanie zasobami ludzkimi w procesach fuzji i przejęć. Kraków: Oficyna Ekonomiczna.

Magala, S. (2011). Kompetencje międzykulturowe. Warszawa: Wolters Kluver Business.

Schmidt, J. (2001). The correct of M\&A begins with HR. HR Magazine.

Schorg, C.A., Raiborn, C. i Massoud, M.F. (2004) Using a "culture audit" to pick M\&A winners. The Journal of Corporate Accounting \& Finance; May/ Jun, 15(4).

Smircich, L. (1983). Concepts of culture and organizational analysis. Administrative Science Quartely, 28.

Stahl, G.K., Mendenhall, M. (2005). Mergers and Acquisitions. Managing Culture and human resources. Stanford: Stanford University Press.

Tewes, Ch. (2001). M\&A and privatisations in Poland. Wiesbaden: Deutsche Universitas - Verlag.

Whitaker, M.K. (2011). Dimensions of organizational culture during a merger: a quantitative perspective from non -managerial employees. Capella University.

Raport Hay Group. (2007). Dangerous Liaisons. Mergers and acquisitions: the integration game.

Raport IBM. (2007). Skok na gtęboka wode: jak z sukcesem przeprowadzić fuzję lub przejęcie.

Raport KPMG. (2011). Rynek fuzji i przejęć, Polska na tle Europy Środkowo-Wschodniej 2010. 